\title{
Corrigendum: Metacognitive awareness and visualisation in the imagination: The case of the invisible circles
}

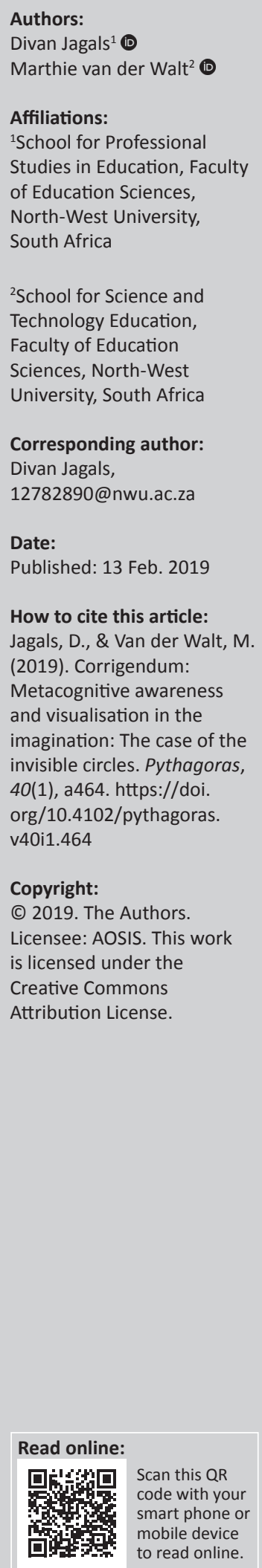

In the author list of this article published earlier, Marthie van der Walt's first name and ORCID were unintentionally misprinted as 'Martha' and 'https://orcid.org/0000-0002-6057-8352'. The author's correct first name is 'Marthie' and the ORCID is 'https: / orcid.org/0000-0002-0465-6600'. The authors sincerely regret this error and apologises for any inconvenience caused. 